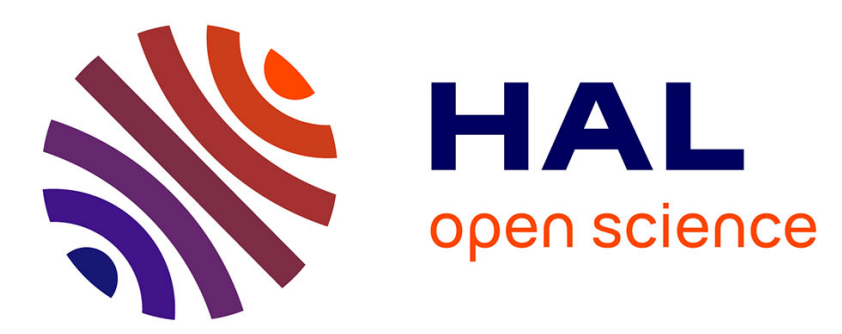

\title{
Linguistic argumentation as a shortcut for the empirical study of argumentative strategies
}

Pierre-Yves Raccah

\section{To cite this version:}

Pierre-Yves Raccah. Linguistic argumentation as a shortcut for the empirical study of argumentative strategies. F. van Eemeren et B. Garssen. Reflections on Theoretical Issues in Argumentation Theory, 28, Springer, 2015, Argumentation Library, 978-3-319-21102-2. halshs-01099482

\section{HAL Id: halshs-01099482 \\ https://shs.hal.science/halshs-01099482}

Submitted on 4 Jan 2015

HAL is a multi-disciplinary open access archive for the deposit and dissemination of scientific research documents, whether they are published or not. The documents may come from teaching and research institutions in France or abroad, or from public or private research centers.
L'archive ouverte pluridisciplinaire HAL, est destinée au dépôt et à la diffusion de documents scientifiques de niveau recherche, publiés ou non, émanant des établissements d'enseignement et de recherche français ou étrangers, des laboratoires publics ou privés. 


\title{
Linguistic argumentation as a shortcut for the empirical study of argumentative strategies
}

\section{PIERRE-YVES RACCAH}

CNRS $L L L-U M R 7270$

University of Orléans

France

pyr@linguistes.fr

\begin{abstract}
A recent interest for the empirical observation of argumentation through institutional practices was underlined by van Eemeren (2010). Since discourses give empirical hints which inform the observer on the institutional conventionalized practices involved in the study of strategic manoeuvring, there must be ways of describing meaning which allows to account for the dynamics of this field: a study of these ways is the object of this paper.
\end{abstract}

KEYWORDS: empirical study of strategic manoeuvring, experiments in semantics, utterance meaning, sentence meaning, empirical observation of institutional practices, indirect observation, inhabited words, points of view, viewpoints semantics.

\section{INTRODUCTION}

Research in argumentation has acknowledged the important role of discourse in the study of argumentative strategies and manoeuvring. This acknowledgement is not recent; however, more recent is the inclusion, within the possible objects of research on argumentation, of the relationship between institutional contexts and argumentative discourse, via conventionalized institutional practices. The recent interest for the empirical observation of argumentation through institutional practices was underlined by van Eemeren (2010, p. 129) in these terms:

$\ldots$ the term argumentation [... also refers to] an empirical phenomenon that can be observed in a multitude of communicative practices which are recognized as such by the arguers. Because these communicative practices are generally connected with specific kinds of institutional contexts [...] they have become conventionalized. Due to this context-dependency of communicative practices, the possibilities for strategic manoeuvring in argumentative discourse in such practices are in some respects determined by the institutional preconditions prevailing in the communicative practice concerned.

This new interest for an empirical approach to the relationship between institutional contexts and argumentative strategies, via communicative practices linked to institutional preconditions, opens a wide and important field of research, as van Eemeren convincingly shows it in his 2010 book.

As van Eemeren pointed out, the empirical study of this multidimensional space is possible because, among other reasons, all the terms of these relations are, at least partially, observable through discourse. Since discourse gives empirical hints to grasp the different facets of this space, it may be argued that there may be a way of describing 
meaning, which would allow to account, at lest partially, for the dynamics of those relations: this would provide a sort of shortcut to the description of argumentative strategies, as they are partially in-formed by the institutions. Obviously, such a shortcut lives aside an enormous part of the field opened by the abovementioned remarks. Nevertheless, for one who is 'only' interested in a better description of the semantics of natural languages, it offers interesting and rich perspectives.

This is what this paper is intended to show. We will also see that this shortcut is not a completely new idea in semantics: I will examine how several ideas borrowed from the paradigm of Argumentation Within Language can be adapted to an empirical study of the relationship between argumentation and the institutional constraints. Finally, I defend the idea that this shortcut is useful also for the one who is engaged in the complete study of the field: since most of what is observable in that field is discourse, it may be useful to make explicit the reasoning which compels to describe the institutional conventions the way we do. A rigorous semantic description is more than useful for this purpose.

Among the various ways of describing meaning that might meet those requirements, I emphasize the interest of several aspects of the so called "View-Point Semantics" (VPS), partially inspired by Mikhail Bakhtin's work on the "inhabited" character of natural language words (see, for instance, Bakhtin (1929, p. 279), as well as by Oswald Ducrot's work on the semantic constraints on argumentative orientation and strength (see, for instance, Ducrot (1988)). In particular, I insist on the technique it provides for, so to speak, extracting ideological and cultural preconditions from discourses, which inform the observer on the institutional conventionalized practices.

\section{FROM STRATEGIC MANOEUVRING TO SEMANTICS (through the route of empiricity...)}

The field of research opened by van Eemeren and Houtlosser (2009) and further investigated by van Eemeren (2010) includes, among other, the study of the multidimensional space of relationships between the different kinds of institutional contexts, the different types of institutionalized purposes, the different aspects of conventionalized communicative practices, the different aspects of communicative activities, and the different types of argumentative strategies. As for the parameters that must be taken into account in order to investigate that field, van Eemeren and Houtlosser (2009, p. 11) circumscribe them in this way:

\footnotetext{
In analyzing the strategic function of the maneuvering that is carried out by making a particular argumentative move, the following parameters need to be considered:

1. the results that can be achieved by the manoeuvring;

2. the routes that can be taken to achieve these results;

3. the constraints imposed by the institutional context;

4. the commitments defining the argumentative situation
}

Following van Eemeren and Houtlosser (and one really wants to follow them -at least on those points), what we have to observe are things like results, routes, constraints and commitments. Moreover, in agreement with one of the cornerstones of pragma-dialectical theories, the empirical study of that field is possible because those 'ingredients' are observable through discourse. Finally, as van Eemeren insisted in his introductory lecture 
at ISSA 2014, the study of strategic manoeuvring must be contextualized, empirical and as formal as possible.

We will see how an empirical semantics of human languages can do the job and collect and organize observational data for a study of strategic manoeuvring that would meet the requirements proposed by van Eemeren and Houtlosser (2009).

\subsection{Empirical observation for strategic manoeuvring and semantics}

From the three theses I underlined (the ingredients, the observability through discourse, and the three desired properties of the study) it follows there must be a way of describing meaning which accounts for how utterances inform with respect to results, routes, constraints and commitments.

The claim is stronger than what it first appears: the term meaning is used here in a technical sense, where it refers to the semantic value of languages units, independently of the situation in which they are used; as opposed to the term sense, (utterance meaning), which we use to refer to the semantic value of utterances in situations.

The reason why that claim has to be acceptable is that the only observable facts that lead a hearer, in a given situation, to reach a particular result, route, constraint or commitment, rather than others, are the linguistic units used in the utterance. Obviously, in other situations, the same linguistic units might (and will) lead the hearer to reach other results, etc., so that the study of strategic manoeuvring really has to be contextualized, in spite of that claim. But, given that in each particular situation, it is the choice of some linguistic unit rather than some other that produce some effect rather than some other, in order to carry an empirical study, it must be acknowledged that a set of instructions which is stable with respect to situations, must be given by the language units which are used in the discourse. Acknowledging this allows to meet the last requirement underlined by van Eemeren: having the study of strategic manoeuvring supported by semantic descriptions (i.e. independent of context), is a necessary (though not sufficient) condition for a possible formal study.

\subsection{Empirical observation in general}

From a more general perspective, I will now address two essential aspects of empirical observation: causality and subjectivity. This will help understand (a) why and how, in spite of the fact that causal relations are not accessible to our sensorial system, they play an essential role in empirical sciences, and (b) why and how, in spite of the necessary radical subjectivity of individual observation, a certain degree of constructed objectivity can be achieved within a community.

\section{a) Causality}

Empirical observation concerning the parameters underlined by van Eemeren and Houtlosser can be expressed by (meta-)statements of the form:

The linguistic segment $\boldsymbol{X}$ used in the institutional situation $\boldsymbol{S}$

produced the effect $\boldsymbol{R}$, with respect to parameter $\boldsymbol{P}$.

As can be seen by the reference to produced effects, these (meta-)statements convey implicit causal attributions. This is not specific to the field of strategic manoeuvring, nor to that of argumentation, and not even to linguistics or any human or social science: 
indeed, any scientific observational statement, like, for instance, "water boils at $100^{\circ} \mathrm{C}$ ", carry implicit causal attributions; in our last example, if we try to substitute " 43 years old" to " $100^{\circ} \mathrm{C}$ ", we immediately understand that the original statement conveys the implicit causal assumption according to which the cause of the boiling is the temperature (and not the age of the technician...).

Now, no scientist and no thinking human being in general would ever pretend they have observed some causal relation with their sensorial apparatus: causal relations are not observable through our sensorial apparatus and causality is always only a hypothesis. Obviously, some causal attributions are more plausible than others, but plausibility is not a proof...

Acknowledging that causal relations are not directly observable through our sensorial apparatus does not imply believing that causality doesn't exist, but only understanding that causal statements cannot be used as empirical evidences

And, since we have just seen that all scientific empirical observational statements convey an implicit causal attribution, it follows that no scientific empirical observational statement can be directly used as an evidence for some theoretical standpoint. This may seem paradoxical, but it is not so. The same idea can be reformulated in another way, which shows an exit to that apparent paradox: 'any statement about the world, which evokes a causal relation between facts of the world, refers to non directly observable facts'. The apparent paradox dissolves itself as soon as we abandon the naïve belief that only material things really exist for science, belief which entails that only direct observation can count as an evidence. This is why sciences, and especially 'hard' sciences have developed a very sophisticated system of indirect observation, including criteria of validity for the causal attributions supposed by that indirect observation.

b) Objectivity and intersubjectivity

Since scientific statements suppose previous causal attribution hypotheses, our perception of the world is significantly influenced by our theoretical biases.

Again, acknowledging that our beliefs about the existence of what we perceive cannot be invoked as a proof of its existence is something different from believing that those beliefs are false. And, in the same way, acknowledging that the way we perceive the world is influenced by our theoretical biases is something different from believing that the world plays no role in the way we perceive it.

Roughly, the essential reason for that difference is that, though we cannot directly access the world (we can only access it through the individual interpretation of what our sensorial apparatus gives), the world accesses our actions and reacts to them. Thus, analyzing what is stable in different selected human actions and in the world reactions to them may give us collective stable elements to make hypotheses about how the world is within that zone of stability.

In Raccah (2005), I showed that an essential scientificity requirement, valid for any kind of science, is that it should provide descriptions of a class of phenomena, in such a way that the descriptions of some of those phenomena provided de dicto explanations for the descriptions of other ones. I also pointed out that fulfilling empiricity requirements could not lead to believe that science describes the phenomena 'the way they are', since one cannot seriously believe that there is a possibility, for any human being, to know the way things are. Though scientific observers cannot prevail themselves of knowing how the world is, they have access to the world through their interpretation of 
the states of their sensorial apparatus: that interpretation often relies on previously admitted scientific - or non scientific- theories.

If we want to apply these requirements to semantic theories, we have to find observable semantic facts, which can be accessed to through our senses. As we will see in the next section, it seems that we are faced with a big difficulty, which might force us to admit that there cannot be such a thing as an empirical semantic theory: we will see that semantic facts are abstract and thus not directly accessible to our sensorial apparatus. We seem to be in a situation in which the very object about which we want to construct an empirical science prevents its study from being an empirical study...

However, if we admit that physics is a good example of empirical sciences, we should realize that we are not in such a dramatic situation. For what the physicist can observe through her/his senses, say, the actual movements of the pendulum (s)he just built, is not what her/his theory is about (in that case, the virtual movements of any existing or non existing- pendulum): the object of physical theories is not more directly accessible to the observers' sensorial apparatus than the object of semantic theories. Physicists use different tricks in order to overcome that difficulty, one of which is the use of indirect observation: some directly observable ${ }^{1}$ entities are considered to be traces of non directly observable objects or events, which, in some cases, are seen as one of their causes, and, in other cases, as one of their effects.

If we are willing to keep considering physics as an empirical science, we are bound to consider that that indirect observation strategy is not misleading; we only have to see how it could be applied to the study of meaning. In order to illustrate how this could be done, I will examine an example and will abstract from it.

\subsection{Empiricity in what concerns the study of human languages semantics}

Now that we have been reminded that (i) causality is not directly observable, (ii) scientific empirical statements of observations suppose causal attributions, (iii) sciences speak of indirectly observable entities embedding relations between directly observable entities, I would like to elaborate on a few interesting properties of the causal attributions used within the sciences of language(s), and, in particular, semantics. This will help understand why semantics can be a shortcut for strategic manoeuvring.

\subsubsection{A few conceptual distinctions}

The concepts I resort to for this study are not all used in a normalized way: in the intent to be understood by different trends of thoughts, I will first insist on several conceptual differences (it should be noted that the terms I used do refer to these concepts may very well not be the ones some or other reader would use. I do not mean to compel them to use the same terms I use rather than the ones they prefer: I only aim at characterizing the concepts and insist on their differences.

\section{a) Several concepts of language}

\footnotetext{
${ }^{1}$ Though I have shown (ibid.) that nothing can be directly observable by a human being (since anything requires the interpretation of the state of our sensorial apparatus), I will use that expression to refer to objects or events whose access is granted by the interpretation of the effect they directly produce on our sensorial apparatus. This terminological sloppiness is introduced for the sake of legibility...
} 
Though it is unavoidable that notions which are deeply related to our ways of thinking are grasped in different manners, according to the differences in those ways of thinking, it is avoidable, and highly desirable (see Pascal 1655, pp. 523-535) to ascertain that these conceptions are about the same concept. In the case of language, the differences in conceptions are frequently altered by an abusive assimilation of three distinct concepts:

(i) something that human beings speak (or write) in, that is usually acquired by all human beings between birth and 24 months, that may serve to communicate, to think, to deceive, etc., that may be different from one group of human beings to another, that may be learnt, taught, etc.; English, French, Spanish, etc. are different instances of this something, which is called "idioma" in Spanish, "langue" in French; the noun referring to it may be pluralized;

(ii) the faculty that human beings have (some people may believe that it is also the case for some animals, robots, gods, etc.), and that enables them to learn, use and possibly forget the something I coined as the first concept; this second object is called "lenguaje" in Spanish, "langage", in French; the noun referring to it cannot be pluralized;

(iii) an abstract system, consciously and deliberately built by a human being, or by a team of human beings, in order to achieve a specific goal or set of goals.

The fact that these three different concepts happen to be called, in English, by the same name is not an evidence for their being the same concept... To avoid such confusions, I will use the term human languages for concept (i), Language Faculty, for concept (ii), and artificial language, for concept (iii).

b) Several concepts of meaning

The difference between a sign and its use in a particular situation is acknowledged by most linguists. However, one of its consequences on the study of semantics and pragmatics, namely the essential difference in nature between utterance meaning and sentence meaning, is not so often taken into account ${ }^{2}$.

In order to fully understand the rest of this paper, it will be necessary to keep this difference in mind: I will speak of utterance meaning in order to refer to the result of some interpretation of a discourse or of an utterance in a particular situation; in contrast, I will speak of sentence meaning in order to refer to the contribution of language units (not only grammatical sentences) to the interpretation of their different possible utterances.

Note that this apparently 'neutral' terminology presupposes that each unit of any language has something stable which is partially responsible for the infinitely many possible interpretations its use may lead to ${ }^{3}$.

\subsubsection{Instructional semantics}

Semantics can thus be conceived of as the discipline which empirically and scientifically studies the contribution of language units (simple or complex) to the construction of the meanings of their utterances in each situation. The contribution of the

\footnotetext{
${ }^{2}$ As far as I know, one of the first explicit modern presentation of the conceptual difference between utterance meaning and sentence meaning is due to Dascal (1983).

3 This very strong claim is evidenced by the fact that any dunce can acquire, and does acquire, a human language in 18-24 months, being exposed only to speech and human attitudes
} 
situations to the construction of utterance-meanings is studied, according to that conception, by pragmatics.

According to that conception of semantics, utterance-meaning is, clearly, the result of a construction achieved by some hearer, construction influenced by the linguistic meaning (sentence-meaning, phrase-meaning) of the language units used in the utterance and by the elements of situation taken into account by the hearer. Diagram 1 illustrates this conception:

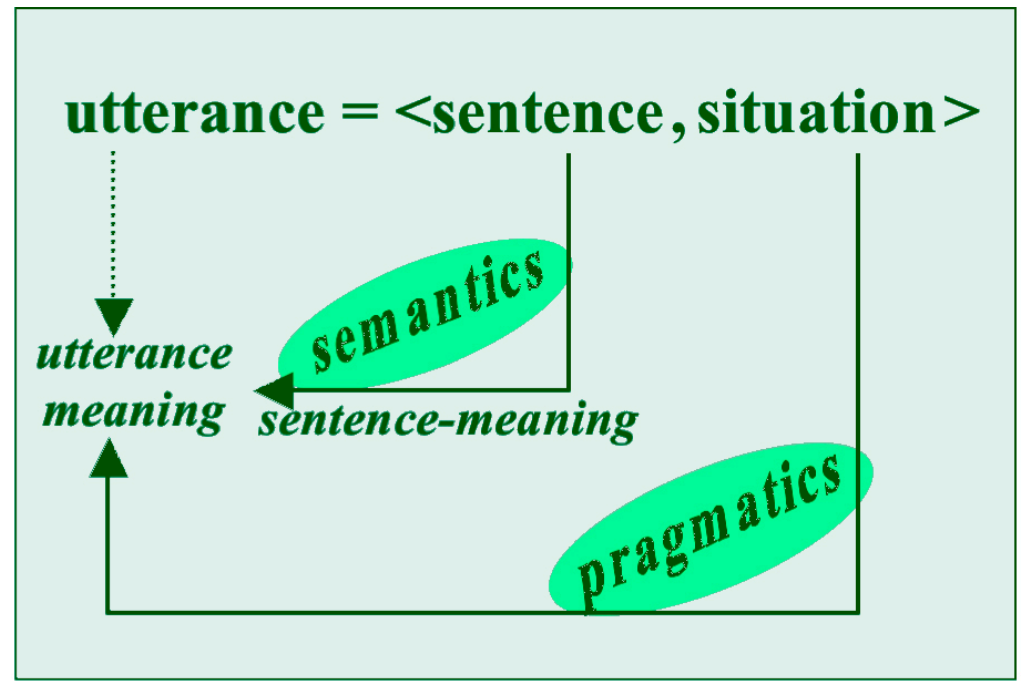

Diagram 1: The determination of utterance-meaning by sentence-meaning and situation

This pre-theoretic way of understanding the canvas of utterance-meaning construction belongs to the instructional semantics trend, as presented, for instance, in Harder (1990, p. 41):

the emphasis is on meaning as something the speaker tells the addressee to do. If A (the addressee) does as he is told (follows the instructions), he will work out the interpretation that is the product of an act of communication

\subsubsection{Causal attributions in semantics, and their essential properties}

Suppose an extra-terrestrial intelligence, ETI, wanted to study the semantics of English and, for that purpose, decided to observe speech situations. Suppose ETI hides in a room where several - supposedly English speaking - human beings are gathered, a classroom, for instance. Suppose now that ETI perceives that John pronounces "It is cold in here". If all of ETI's observations are of that kind, there is no chance that it can formulate grounded hypotheses about the meaning of the sequence it heard. For what can be perceived of John's utterance is only a series of vibrations, which, in themselves, do not give cues of any kind as to what it can mean (except for those who understand English and interpret the utterance using their private know-how). If ETI wants to do its job correctly, it will have to use, in addition, observations of another kind. Intentional states are ruled out since they are not directly accessible to the observers' sensorial apparatus. It follows that we will have to reject any statement of the kind: "the speaker meant so and so", or "normally when someone says XYZ, he or she wants to convey this or that idea" 
or even (in case the observer understands English) "I, observer, interpret XYZ in such and such a way and therefore, that is the meaning of XYZ". ETI will have to observe the audience's behaviour and see whether, in that behaviour, it can find a plausible effect of John's utterance: it will have to use indirect observation. The fact that it may be the case that no observable reaction followed John's utterance does not constitute an objection to the indirect observation method: it would simply mean that ETI would have to plan other experiments. After all, even in physics, many experiments do not inform the theorists until they find the experimental constraints that work.

Before we go further, let me insist and emphasize that we have just seen that the different 'popular learned conceptions' ${ }^{4}$ of semantics are wrong. Indeed, the observable phenomena of semantics (i) cannot be directly meanings, since these are not accessible to our sensorial apparatus; (ii) they are not just utterances, since that would not be enough to describe meaning phenomena; (iii) they are not pairs consisting of utterances and 'intended meanings', since such intentional things are not accessible to empirical observation. In our extra-terrestrial example, we suggested that they are pairs consisting of utterances and behaviours.

I will take that suggestion as seriously as possible: in the rest of this section, I examine how to constrain the relationship between utterances and behaviours, and sketch some of the consequences of this choice.

a) The causal attribution hypothesis

Suppose that, in our example, ETI notices that, after John's utterance, the following three actions take place: (i) Peter scratches his head, (ii) Paul closes the window and (iii) Mary writes something on a piece of paper. We all know (actually, we think we know, but we only believe...) that the correct answer to the question "what action was caused by John's utterance?" is most probably "Paul's". However, ETI has no grounds to know it and, in addition, it may be the case that Paul closed the window not because of John's utterance (which he may even not have heard), but because he was cold, or because there was too much noise outside to hear what John was saying... Obviously, the most plausible hypothesis, in normal situations, is the one according to which Paul's action was caused by John's utterance; but the fact that it is plausible does not make it cease to be a hypothesis...

Thus, before ETI can continue its study, it must admit the following general hypothesis

\section{$\mathrm{H}_{0}$ : Utterances may cause behaviours}

Moreover, in each experimental situation $s$, ETI must make specific hypotheses $\mathrm{h}_{S}$ which particularise $\mathrm{H}_{0}$ in the situation $s$, and relate particular actions with the utterance under study (an aspect of van Eemeren's contextualization).

It is important to remind that $\mathrm{H}_{0}$ and the different $\mathrm{h}_{\mathrm{S}}$ are not facts about the world but hypotheses: they do not characterise the way things are but rather the way things are conceived of in our rationality.

b) The non materiality hypothesis

\footnotetext{
${ }^{4}$ That is, the conception an educated person could have about semantics without having learnt and reflected about it previously... This is, it must be admitted, the conception held by many people who speak or write about language!
} 
Let us suppose that ETI shares with us the aspects of our contemporary occidental rationality expressed by $\mathrm{H}_{0}$. This would not prevent it from believing that the way John's utterance caused Paul's action is that the vibrations emitted by John during his utterance physically caused Paul to get up and close the window. Though it hurts our contemporary occidental rationality, this idea is not absurd: the fact that we simply cannot take it seriously does not make it false ${ }^{5}$. Moreover, utterances do have observable physical effects: a loud voice can hurt the hearers' ears, specific frequencies can break crystal, etc. What our rationality cannot accept is the idea that the linguistic effects of the utterances could be reduced to material causality. In order to rule out this idea, we need another hypothesis, which is also characteristic of our rationality rather than of the state of the world:

\section{$\mathrm{H}_{1}$ : The linguistic effects of an utterance are not due to material causes}

As a consequence of $\mathrm{H}_{1}$, if we cannot believe that the observable actions caused by an utterance are due to its materiality, we are bound to admit that they are due to its form. In our rationality, the causal attribution requested by $\mathrm{H}_{0}$ is constrained to be a formal causality.

c) The non immediateness hypothesis

If we use the term sentence to refer to a category of form of utterances, we start to be in the position to fill the gap between what we can observe (utterances and behaviours) and what we want semantics to talk about (sentences and meanings). However, there is yet another option that our rationality compels us to rule out: ETI could accept $\mathrm{H}_{1}$ and yet believe that though the causality that links John's utterance to Paul's action is not material, it directly determined Paul's action. That is, one could believe that John's utterance directly caused Paul to close the window, without leaving him room for a choice. This sort of belief corresponds to what we can call a 'magic thinking'; indeed, in Ali Baba's tail, for instance, there would be no magic if the "sesame" formula were recognised by a captor which would send an "open" instruction to a mechanism conceived in such a way that it could open the cave. The magical effect is due to the directedness of the effect of the formula. It is interesting to note that this feature of our rationality, which compels us to reject direct causality of forms, is rather recent and probably not completely 'installed' in our cognitive systems: there are many traces in human behaviour and in human languages of the 'magic thinking'. From some uses of expressions like "Please" or "Excuse me" to greetings such as "Happy new year!", an impressing series of linguistic expressions and social behaviours suggests that, though a part of our mind has abandoned the 'magic thinking', another part still lives with it. Think, for instance, about the effects of insults on normal contemporary human beings...

However, for scientific purposes, we definitely abandoned the 'magic thinking' and, again, since it is a characteristic of our rationality and not a matter of knowledge about the world, no observation can prove that it has to be abandoned: we need another hypothesis, which could be stated as follows:

\section{$\mathrm{H}_{2}$ : The directly observable effects of utterances are not directly caused by them}

\footnotetext{
${ }^{5}$ Some Buddhist sects seek the "language of nature" in which the words emit the exact vibrations which correspond to the objects they refer to... Even though most of us, occidental thinkers, reject the belief underlying that quest, there is no ground to profess that the belief is silly independently of our set of beliefs.
} 
The acceptance of that "anti-magic" hypothesis has at least two types of consequences on the conception one can have of human being.

The first type of consequences pertains to ethics: if utterances do not directly cause observable effects on human actions, no human being can justify a reprehensible action arguing that they have been told or even ordered to accomplish them. If a war criminal tries to do so, he or she will give the justified impression that he or she is not behaving like a human being, but rather like a kind of animal or robot. As human beings, we are supposed to be responsible for our actions; which does not mean that we are free, since a reprehensible decision could be the only way of serving vital interests. Though this type of consequences of $\mathrm{H}_{2}$ are serious and important, they do not directly belong to the subject matter of this paper and we will have to end the discussion here. However, we think they were worth mentioning...

The second type of consequences of $\mathrm{H}_{2}$ concern the relationship between semantics and cognitive science. Indeed, $\mathrm{H}_{2}$, combined with $\mathrm{H}_{0}$ and $\mathrm{H}_{1}$, can be seen as a way of setting the foundations of a science of human cognition and of picturing its relationship with related disciplines. If we admit, in agreement with $\mathrm{H}_{0}, \mathrm{H}_{1}$ and $\mathrm{H}_{2}$, that an utterance may indirectly and non materially causes an action, we are bound to accept the existence of a non physical causal chain linking the utterance to the action, part of that chain being inaccessible to our sensorial apparatus. The object of semantics is the first link of the chain; the first internal state can be seen as the utterance meaning. The action is determined by a causal lattice in which the utterance meaning is a part, and which includes many other elements and links; none of these elements or links are directly observable, though indirect observation can suggest more or less plausible hypotheses about them. Different theoretical frameworks in cognitive science construe that causal lattice in different ways; they also use the variations of different observable parameters in order to form these hypotheses. In our example, the only two directly observable parameters were utterances and actions, for the part of the lattice that we are interested in is the chain that links utterances to actions. However, other kinds of cognitive science experiments could be interested in studying the variations of other directly observable parameters, such as electrical excitation, visual input, outside temperature, etc. for the beginning of the chain and movement characteristics, body temperature, attention, etc. for the end of the chain ${ }^{6}$.

Note that the fact that cognitive science and semantics may share experimental devices is not sufficient to adhere to the present fashion and suggest that there can be a "cognitive semantics": the object of semantics (the link between utterances and utterance meanings, as it is inscribed in languages units) does not belong to the causal lattice which constitutes the object of cognitive science ${ }^{7}$.

\section{STRATEGIC MANOEUVRING, HUMAN LANGUAGES \& ARGUMENTATION}

From the necessity of devising experiments providing indirect observation for semantics, as analyzed above, many consequences follow, from many different points of view. For the purpose of this paper, I would like to insist on two of them, which are related to the

\footnotetext{
${ }^{6}$ I obviously didn't choose realistic nor very interesting parameters... but my purpose is only illustrative.

${ }^{7}$ See Raccah (2011) for more about this subject.
} 
connection between strategic manoeuvring and semantic approaches to argumentation: namely the essential role of discourses analysis, and the essential insufficiency of ordinary corpora.

\subsection{The essential role of discourses analysis in semantics}

As acknowledged by the pragma-dialectical approach to strategic manoeuvring, most, if not all, of what we know about results, routes, constraints and commitments involved in the that is carried out by making an argumentative move, we know it through the interpretation of texts or discourses. It follows that, if we don't use an empirically grounded formal model in order to account for how this knowledge is built out of these texts and discourses, the essential knowledge used for describing argumentative strategies will remain intuitive.

In order to account for how this knowledge is built, out of the interpretation of texts and discourses, the semantic models that can be used must enable to describe how languages units impose the construction of the particular senses (utterance meanings), in the situations in which they are uttered, senses which constitute the different pieces of that knowledge. And, in order to allow such descriptions, the language units have to crystallize some aspects of the socialized world which constitute the institutional situation. Diagram 2 illustrates this point.

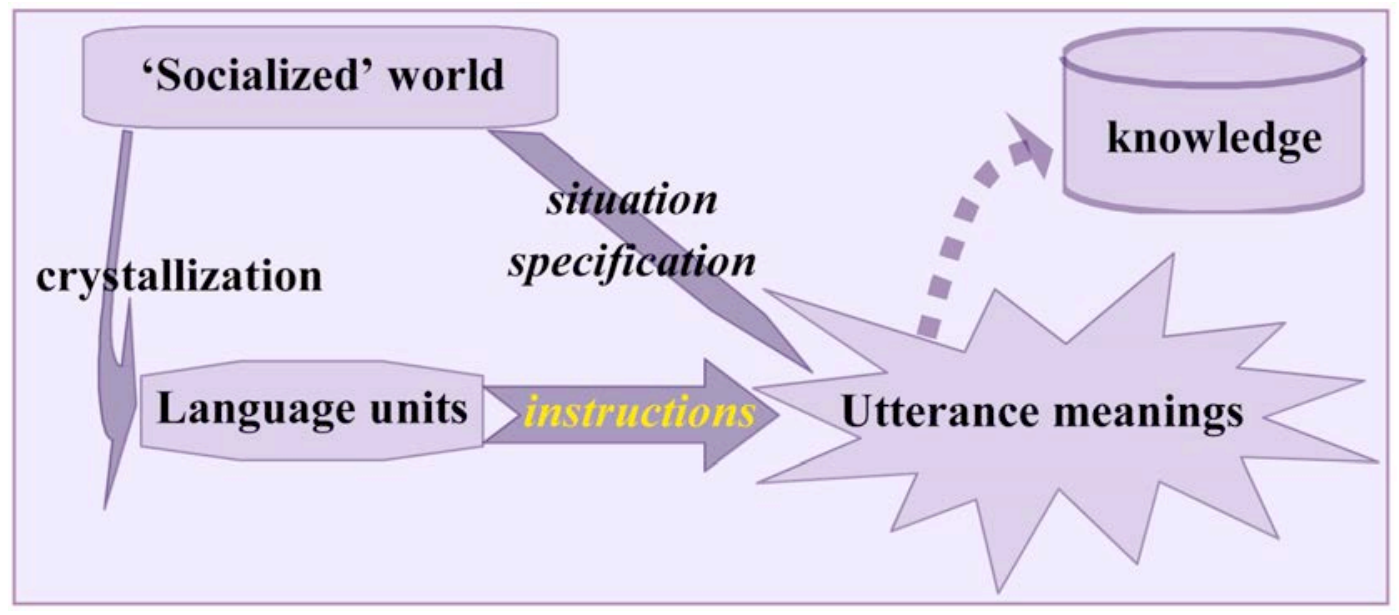

Diagram 2: from situations and language units to knowledge concerning strategic manoeuvring

\subsection{About corpora}

The second consequence of this causal study which I would like to emphasize concerns the kind of corpora that can be useful for an empirical study of strategic maneuvering through semantics. The requirements for such corpora are limited to the ones for semantic corpora, since any discourse and any text refers to the institutional constraints on its own interpretation. However, these 'limited' requirements that must meet a corpus in order to be usable for an empirical study of semantics are not so weak and, actually, are very seldom met in the corpora used in the literature.

Indeed, ordinary corpora provide only (in the best cases) one half of the empirical data required to study semantics: they usually only provide the linguistic units that have 
been used (the signifier), but do not give cues for the utterance meanings that have bean actually constructed in the real situation in which they have been used. This leaves the second half of the necessary data to the observer's intuition. The fact that observer's intuitions are usually rather good does not help: on the contrary, it makes the observer rely on these intuitions without even noticing it. In order to illustrate this point, one only needs to imagine a physicist's reaction to another physicist claiming "I know where the cannon ball will fall, so I don't have to tire myself to examine what is happening in the field"...

Obviously, the actual interpretation that a reader or a hearer made in the actual situation in which those linguistic units were used (like any interpretation whatsoever) is not accessible through our sensorial apparatus. Therefore, no corpus could possibly provide it. However, it is the burden of the observers to justify the interpretations they assign to those texts and discourse. Again, indirect observation is necessary: a useful corpus for semantics should contain cues for assessing the correctness or, at least, the plausibility of hypotheses on what has been understood.

\section{PROVISIONAL CONCLUSIONS, AND PERSPECTIVES}

I will conclude underlining some of the consequences of the ambition to use semantics in order to more formally and more empirically access institutional knowledge within the study of strategic manoeuvring.

In this study, we saw that, if we want to take seriously the findings of the pragmadialectical approach to strategic manoeuvring, we must be in the position to take into account the institutional preconditions prevailing in the communicative practice, preconditions which can be observed mainly through discourses and texts. For that reason, we must be able to, so to speak, extract those preconditions out of these discourses and texts, as rigorously as possible; in particular, in order to limit the role of intuition, we need a semantic model which can determine the contribution of language units to the assessment of those preconditions.

Neither cognitive semantics nor truth-conditional semantics can do the job because the descriptions they provide have nothing to do with socialized ways of understanding the institutions: what is needed is an instructional semantics that accounts for how the languages units influence the hearer's ways of seeing the role of institutions, or, from a complementary point of view, how the languages units reveal the speakers' ways of understanding the impact of institutions. As a consequence, what is needed is a semantics that assigns socialized points of view to language units, constraints on points of view to connectors and operators, in order to allow to compute the points of view suggested by more complex language units. Given that causal relations are not observable though our sensorial apparatus, particular attention must be paid to the refutability of each observational statement. Moreover, given that the interpretation that was actually built out of a discourse or a text is not directly accessible to observation, particular attention must also be paid to the justification of the interpretation assigned to the triple $<$ language unit, situation, addressee $>$.

Such semantic models, called ViewPoint Semantics (VPS), have been developed and are mainly used to extract knowledge and/or ideologies from texts and discourses. 
Their use for assessing institutional preconditions prevailing in the communicative practice, in order to study strategic manoeuvring, is promising, from a practical point of view, and inspiring, from a theoretical point of view.

\section{REFERENCES}

Bakhtin, M. M. (1929). Bakhtine Mikhail Mikhaïlovitch (1929). Problemy tvorchestva Dostoevskogo. Leningrad 1929. $2^{\text {nd }}$ edition: Probemy poetiki Dostoevskogo. Moscow, 1963. Translated to French by Kolitcheff, Isabelle. La poétique de Dostoievski. Paris, 1970-1998; Le Seuil.

Dascal, Marcelo (1983). Pragmatics and the philosophy of mind 1: Thought in Language. Amsterdam and Philadelphia: John Benjamins.

Ducrot, O. (1988). Topoï et formes topiques, Bulletin d'études de linguistique française de Tokyo 22, $1-14$.

Eemeren, F. H. van (2010). Strategic maneuvering in argumentative discourse. Extending the pragmadialectical theory of argumentation. Amsterdam and Philadelphia; John Benjamins.

Eemeren, F. H. van, \& Houtlosser, (2009). Strategic maneuvering. Examining argumentation in context. In F. H. van Eemeren (Ed.), Examining Argumentation in Context. Fifteen Studies on Strategic Maneuvering. Amsterdam and Philadelphia; John Benjamins.

Harder, Peter (1990). The Pragmatics and Semantics of Reference. Copenhagen studies in language, 13, 41-78.

Pascal, B. (1655). De l'esprit géométrique. Fragments edited by Ernest Havet in Pensées de Pascal publiées dans leur texte authentique. Paris, 1883; Delagrave.

Raccah, P.-Y. (2005). What is an empirical theory of linguistic meaning a theory of? In Z. Frajzyngier et al. (eds.). Diversity and Language Theory. Studies in Language Companion Series; Amsterdam and Philadelphia; John Benjamins.

Raccah, P.-Y. (2011). Linguistique critique : une exploration cognitive. Intellectica 56: 305-314. Special issue: Linguistique cognitive : une exploration critique, dir.: Jean-Baptiste Guignard. 